\title{
Mi cigarro, mi Singer, y la revolución mexicana: la danza ciudadana de Nellie Campobello*
}

\begin{abstract}
Mary Louise Pratt**
Resumo

La autora propone en estas páginas trazar el perfil de la revolución mexicana en las dos obras narrativas principales de Nellie Campobello, Cartucho de 1931 y Las manos de mamá de 1937, y vincular estas con su práctica dancística desarrollada durante los mismo años. El articulo subraya el experimentalismo de ambas, enfocando la búsqueda de una forma alternativa de historicidad para contar los eventos de la revolución y el desarrollo de una óptica feminocéntrica sobre el estado de guerra. Finalmente, trata de situar la obra de Campobello dentro de una lectura de la revolución mexicana como una revolución sexual.
\end{abstract}

Palavras-chave: Gênero, Nellie Campobello, Revolução Mexicana, Revolução Sexual, Literatura.

\footnotetext{
* Recebido para publicação em outubro de 2003, aceito em janeiro de 2004. Agradezco a Carmen Ramos Escandón la oportunidad de presentar este trabajo en el simposio sobre "Revolucionarios o Revolucionados? Nuevos enfoques sobre la revolución mexicana", CIESAS DF; a Gabriela Cano su lectura cuidadosa de este texto, sus excelentes sugerencias, y la oportunidad de compartirlo con su seminario en el Centro de Estudios de Género, UNAM; y al Instituto de Estudios Estéticos,Universidad de Guadalajara, por la oportunidad de reflexionar sobre la danza en el simposio "El Arte como Objeto de Investigación." Este trabajo se inició en CIESAS-Occidente, Guadalajara, y se terminó en el Center for Advanced Studies in the Behavioral Sciences, Stanford, California.

** Stanford University.mlp7@nyu.edu
} 
Mi cigarro, mi Singer, y la revolución mexicana

My Cigar, My Singer and the Mexican Revolution: Nellie Campobello's Citizen Dance

\begin{abstract}
The author's purpose here is to trace the profile of Mexican revolution in Nellie Campobello's main narratives works, 1931 Cartucho and 1937 Las manos de mamá, linking them with her dancing practices developed throughout those same years. This article intends to underline the experimentalism of both, focusing the search for an alternative type of historicity in order to tell the events of the revolution and to develop a feminine-centric view on the war state. Finally, it situates Campobello's work in an understanding of the Mexican revolution as a sexual revolution.
\end{abstract}

Key words: Gender, Nellie Campobello, Mexican Revolution, Sexual Revolution, Literature. 
Gracias a los aportes de la nueva historiografía, es casi un cliché ahora abrir un ensayo observando que en el proceso de producción de las historias oficiales las mujeres tienden a "desaparecer". El nombre de Nellie Campobello (1900?), autora de tres importantes textos literarios y documentales sobre la revolución en el norte de México, poeta, fundadora de la Escuela Nacional de Danza y del Ballet de la Ciudad de Mexico, sirve bien para acordarnos que estas desapariciones no consisten simplemente en un silencioso deslizar de nombres de la memoria, de la página, de debajo de la foto. Igual que las desapariciones de ciudadanos desterritorializados bajo las dictaduras, son procesos materiales y existenciales violentos, escandalosos. Los procesos discursivos e institucionales que marginan el actuar histórico de las mujeres no se pueden separar de las formas de violencia física y psíquica que ellas enfrentan en la existencia vivida. Son cuestiones de ciudadanía. Qué bien nos lo demuestra la historia recente de Nellie Campobello, resuscitada en marzo de 1998 en serie de artículos publicados en La Jornada por la periodista Raquel Peguero. ${ }^{1}$ Peguero recuperó la dramática historia del secuestro, encerramiento y despojo de la artista por una pareja de exestudiantes encargada de su mantenimiento, y de su completa desaparición en 1985, después del fracaso de un pleito legal de parte de amigos y familiares que buscaban rectificar su situación.

Los detalles son kafkianos: el pleito falló porque los supuestos secuestradores/abusadores se negaron a presentar a Campobello en la corte para que se verificara su estado. Es decir, su no-aparición se interpretó legalmente (dos jueces contra uno) no como evidencia de posible secuestro y abuso, sino como ausencia de evidencia. ${ }^{2}$ La desaparición se selló por la ley y a

1 Peguero, Raquel. La Jornada, marzo 23, 26, 27, 28 de 1998. Vea http://serpiente.dgsca.unam.mx/jornada/1998/mar98/980323/robado.html.

2 Según la juez que presidió el caso, la defensa finalmente presentó a Campobello en la corte y cuando la juez, viendo su condición debil y desorientada, ordenó que se la tomara bajo custodia de la corte, los guardaespaldas del abogado la levantaron físicamente y la sacaron del juzgado, 
Mi cigarro, mi Singer, y la revolución mexicana

partir de esa fecha ni su propia familia pudo obtener noticias de ella, a pesar de repetidas tentativas. ${ }^{3}$ Después de 13 años sin noticias directas de ella, años durante los cuales sus secuestradores continuamente confirmaban que estaba en vida y en buenas condiciones, por fin en diciembre de 1998 en la ciudad Progreso de Obregón, estado de Hidalgo representativos la Comisión de Derechos Humanos encontraron una tumba marcada con las iniciales de Nellie Campobello, y un acta de defunción constatando su muerte el 9 de julio de 1986. Como dijo E. Poniatowska, "le escamitaron su propia muerte". ${ }^{4}$ Nellie Campobello no tuvo la muerte que merecía, es decir, una muerte que le concediera su entrada a la Historia. Como para subrayar las ásperas realidades del mundo de las letras latinoamericanas, en los mismos números de La Jornada donde aparecieron los grotescos detalles sobre Campobello, en primer plano se celebraba con fotos el cumpleaños de Octavio Paz y una reunión de Saramago, Fuentes, y García Márquez donde este opina "que nos lean los jóvenes significa menos maneras de morir."

Obviamente, la desaparición de Nellie Campobello hubiera sido más completa todavía si no fuera por dos mujeres con acceso a formas de autoridad pública: la juez Margarita Guerra Tejeda que persiguió el caso en 1985, y para quién el fallo fue "una pesadilla", y la periodista Peguero que resuscitó la historia en 1998. Algo parecido se podría decir respeto a la extraordinaria

mientras todos los guardias de la corte misteriosamente habían desaparecido. La juez opina que los jueces que tomaron la decisión final fueron comprados por el abogado, un notorio defensor de narcotraficantes.

3 Las noticias más recientes publicadas en Proceso (18 octubre de 1998) narran un esfuerzo inútil por parte de la Comisión de Derechos Humanos del DF para hacer contacto con Campobello a través del supuesto secuestrador, Enrique Fuentes León. Este, después de un recorrido de horas por la ciudad de Mexico, simplemente se negó a llevar los investigadores al supuesto paradero de Campobello.

4 La Jornada, 28 marzo de 1998.

5 La Jornada, 26 marzo de 1998. 
producción literaria de Campobello. Por influencia de Berta Gamboa, una de las primeras criticas a identificar (en 1935) la "novela de la revolución mexicana" como un corpus literario, Nellie Campobello entró en ese corpus. Es la única autora femenina de los 12 incluídos en la canónica edición Aguilar de La novela de la revolución mexicana preparada por Gamboa y Antonio Castro Leal. ${ }^{6}$ En la práctica, como ocurre con frecuencia uno piensa en Gabriela Mistral o Clorinda Matto de Turner Campobello ha sido "muchas veces mencionada y pocas veces estudiada". ${ }^{7}$ Uno de los grandes canonizadores de la literatura mexicana, el estadounidense John Brushwood concluyó que la contribución de Campobello al tema de la revolución fue "casi nula". ${ }^{8}$ El estudio serio de la obra de Campobello comienza a fin de los 70, cuando una generación de críticas/os empezaron a reescribir la historia de las literaturas latinoamericanas incorporando la producción femenina. ${ }^{9}$ Para una de ellos, la

6 Esta colección atestigua otra desaparición femenina en el mundo de las letras, la de la misma Berta Gamboa. Aunque, como informa una nota preliminar, Gamboa había terminado casi todo el trabajo de selección, edición y documentación antes de que su trabajo fuera interrumpida por la muerte, su nombre no aparece en ningún lugar en la obra, que se atribuye universal e injustamente a Castro Leal.

7 DE BEER, Gabriella. Nelly Campobello, escitora de la Revolución Mexicana. Cuadernos Americanos 223, 1979, p.212. Ver también su Nellie Campobello's Vision of the Mexican Revolution. The American Hispanist 4, Mar-Apr 1979, pp.34-35.

8 BRushwood, John. Mexico in its Novel. Austin, UT Press, 1966, citado en MATTHEWS, Irene. Mothering in war: Two "case studies" from Mexico and Guatemala. En COOKE, Miriam y WoOllacotT, Angela. (eds.) Gendering War Talk. Princeton, Princeton UP, 1993, pp.148-73.

9 Además de los artículos ya mencionados de De Berr y Matthews, la bibliografía crítica sobre Campobello incluye los siguientes trabajos: MEYER, Doris. Nellie Campobello's Las manos de mamá: A rereading. Hispania 68, diciembre de 1985, pp.747-52; OyARZún, Kemy. Mujer, memoria, historia: Cartucho de Nellie Campobello, en su colección The Latin American Short Story. Riverside, Latin American Studies Program, 1997; y Identidad femenina, genealogía mitica, historia: Las manos de mamá. Revista de Crítica Literaria latinoamericana \#43- 
Mi cigarro, mi Singer, y la revolución mexicana

chilena Kemy Oyarzún, Campobello "afirma la presencia de un nuevo sujeto en las letras de la nación mexicana" y "marca un cortocircuito en el sistema patriarcal mexicano y latinoamericano". ${ }^{10}$ Creo que Oyarzún tiene razón, pero añadiría que los sistemas tienden a buscar eliminar sus cortos circuitos $-y$ que la voz de ese nuevo sujeto, por falta de eco, se apagó. ${ }^{11}$

Mi propósito en estas páginas es trazar el perfil de la revolución mexicana en las dos obras narrativas principales de Nellie Campobello, Cartucho de 1931 y Las manos de mamá de 1937, y vincular estas con su práctica dancística desarrollada durante los mismo años. Propongo subrayar el experimentalismo de ambas, enfocando la búsqueda de una forma alternativa de historicidad para contar los eventos de la revolución y el desarrollo de una óptica feminocéntrica sobre el estado de guerra. Finalmente, trataré de situar la obra de Campobello dentro de una lectura de la revolución mexicana como una revolución sexual. ${ }^{12}$ Contextualizaré mi argumento en unas reflexiones acerca de la historiografía convencional de las sociedades en estado de guerra. Como epígrafe, se puede evocar una foto hecha in 1928 en México por Tina Modotti, titulada "Mujer con bandera".

44, 1996, pp.181-99. El reciente libro magistral de Irene Mathews (Nellie Campobello: La centaura del norte. Mexico, Cal y Arena, 1997) es el primer estudio extenso sobre Campobello, integrando imprescindibles datos biográficos con analises de la obra literaria y la carrera danzística de Campobello. Mathews estuvo entre las últimas personas que entrevistaron a Campobello antes de su desaparición. Sobre la historia de Campobello en el mundo de la danza en México, vea QuirOz, Margarita Tortajada. Danza y poder. Mexico, Institution Nacional de Bellas Artes, 1995 y Dallal, Alberto. La danza en México en el siglo XX. Consejo Nacional para la Cultura y las Artes, 1997. Un libro en prensa por el Prof. Max Parra llevará dos capítulos sobre la obra literaria de Campobello.

${ }^{10}$ OYARZÚN, K. Identidad femenina, genealogía mitica, historia... Op. cit., pp.189, 197.

${ }^{11}$ Con respeto a este punto, es decir, la falta de progenia literaria, la comparación de Campobellos con Juan Rulfo es interesante.

${ }^{12}$ Debo a Carlos Monsiváis la mención de este concepto, en una brillante conferencia en la Universidad de Stanford, noviembre de 1997. 
Mary Louise Pratt

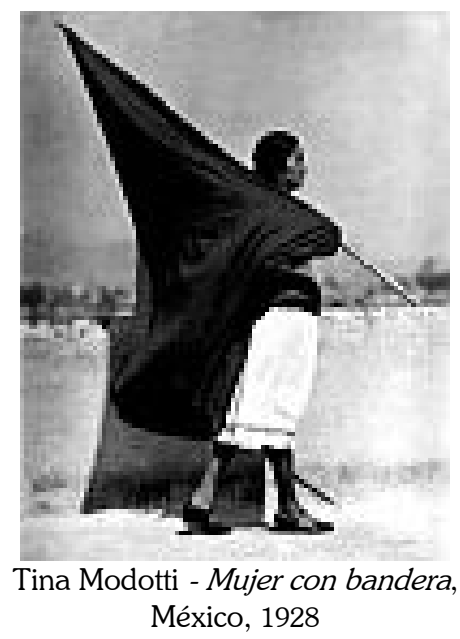

Sería fácil ver en esta foto una representación de la mujer revolucionaria, o la mujer en la nueva nación revolucionada. Pero tal lectura presupone mucho. ¿No es posible también que la foto plantea el enigma de la mujer en la revolución y en la nación revolucionada? La imágen viene cargada de una serie de vacíos semióticos que la/el lectora puede o llenar o interrogar: ¿Qué bandera lleva la mujer? - Lo único cierto es que no es una nacional. ¿Es roja? - La foto está en blanco y negro. ¿Por qué la lleva? ¿Como marca de afiliación política, o como sarape? ¿Es revolucionaria, o tenía frio? ¿Dónde se encuentra la colectividad con la cual la bandera supuestamente la identifica? ¿Será que el mensaje revolucionario que expresa esta mujer es su soledad misma: el hecho de que ella (ya) no pertenece a nadie?

\section{Género y estado de guerra}

Desde Tucídides a Tolstoy al cine más reciente, los estados de guerra son un tema de preferencia en occidente para la narrativa histórica, sea documental o ficticia. Las historias de guerra están marcadas casi siempre por un androcentrismo 
Mi cigarro, mi Singer, y la revolución mexicana

aplastante, tendencia atestiguada rotundamente por la narrativa e historiografía de la Revolución mexicana. Detrás de este androcentrismo están los hechos de que (a) en occidente los productores de la Historia son los ciudadanos; los no-ciudadanos - en el pensamiento clásico, las mujeres, los niños y los esclavos no son actores de la Historia ${ }^{13}$; (b) el papel de soldado se considera en occidente como la manifestación más pura de la ciudadanía $^{14} ;$ y (c) las sociedades en estado de guerra se segregan por género, generación y espacio, polarizando la distribución de actores. Los hombres-ciudadanos jóvenes parten al campo de batalla y al cuartel; las mujeres, con niños y ancianos, siguen ocupando la ciudad y el hogar.

En la historiografía normativa occidental, en estados de guerra el locus donde se produce la Historia es la esfera militar (el "teatro de guerra"). La esfera doméstico-civil se codifica como "lo que quedó atrás", un espacio que a menudo se imagina como suspenso en el tiempo, esperando que se resuelva el conflicto y se restaure el viejo orden, o el nuevo. Este mapa ideológico del estado de guerra parece ser un variante del paradigma más general que identifica el actuar masculino como productivo y el actuar femenino como reproductivo. Las imagenes oficiales de la mujer en estado de guerra - las devotas esposas, madres, hermanas y novias tejiendo calcetines, prendiendo velas o enrollando vendas - normalizan esta vision reproductiva del espacio cívico-doméstico. Siguen identificando a la mujer por su relación al hombre-soldado, y su trabajo como reproductivo. La muy celebrada imagen de la soldadera que se oficializó en el caso de la revolución mexicano no es una excepción. Igual de devota, en la iconografía la soldadera ocupa la margen o el trasfondo del escenario de guerra y mantiene el papel del trabajo reproductivo. Produce una esfera domestica al borde del espacio militar.

${ }^{13}$ Esta configuración aparece, por ejemplo, en la Política de Aristóteles.

${ }^{14}$ Anderson, Benedict. Comunidades imaginadas: Reflexiones sobre el origen y la difusión del nacionalismo. México, FCE, 1993. 
Mary Louise Pratt

Esta imagen de la sociedad en estado de guerra se podría resumir en el siguiente esquema. Subrayo que el esquema intenta resumir, esquemáticamente, la manera en que la historiografía convencional tiende a imaginar la sociedad en estado de guerra.

\author{
Espacio militar \\ hombres/ciudadanos \\ campo (de batalla) \\ cuartel \\ productores \\ pelear \\ en escena \\ soldado
}

\author{
Espacio doméstico-civil \\ mujeres/no ciudadanos \\ ciudad (pueblo) \\ hogar \\ reproductores \\ apoyar, esperar \\ fuera de escena \\ esposa/hermana/novia/madre de soldado
}

En su estudio La mujer en la revolución mexicana Ángeles Mendieta Alatorre ofrece una lista honorífica de los tipos de participación de las mujeres en la revolución mexicana que afirma esta imagen:

\section{Compendio de la participación de la mujer en la Revolución}

1. Formaron o colaboraron en clubes liberales, antirreeleccioistas o de cooperación de los grupos armados.

2. Fundaron periódicos de oposición al régimen o en defensa de las clases devalidas. Asimismo, escribieron numerosos artículos.

3. Su ayuda en los complots, paso de armas, correo y difusión de noticias fue verdaderamente admirable.

4. Como enfermeras estuvieron en los puestos de avanzada o en lugares fijos establecieron hospitales de sangre.

5. Con generosidad se desprendieron de sus fortunas, su bienestar y su propia libertad, para colaborar en la causa que juzgaban justa. 
Mi cigarro, mi Singer, y la revolución mexicana

6. Mantuvieron el espíritu de la lealtad y protesta contra la usurpación huertista.

7. Tomaron las armas y combatieron junto a sus esposos y sus hijos.

8. Sostuvieron la moral de la tropa, caminando en la retaguardia, buscando alimento y escuchando noticias. 9. Bordaron estadartes, confeccionaron banderas, desempeñaron comisiones importantes o mínimas; repartieron proclamas y multiplicaron los manifiestos. 10. Colaboraron en la redacción de escritos importantes. 11. Firmaron manifiestos públicos o hicieron acto de presencia en manifestaciones peligrosas. ${ }^{15}$

Creo que hace falta modificar esta imagen para que refleje aspectos adicionales del proceso histórico de la guerra. Por ejemplo, una de las distorciones del esquema convencional es que al identificar a las mujeres unicamente por sus relaciones de apoyo (reproducción) con respecto a los hombres, se oscurece su obligación de reemplazar a los hombres durante el estado de guerra en muchas esferas incluyendo la esfera productiva. Bien se sabe que la guerra inserta a las mujeres en sectores de producción y de ciudadanía que antes pertenecían a los hombres, ofreciéndoles e imponiéndoles nuevas formas y poderes de actuar, nuevas responsabilidades, nuevas experiencias, nuevos sufrimientos. A nivel material, la partida de los hombresciudadanos a la guerra obliga a los que "quedan atrás" a sustituir al hombre-ciudadano en la esfera de la producción, sea agrícola o industrial; en la dirección de la familia; en el manejo de los negocios; y en cargas públicas. Estas obligaciones vienen encima del trabajo llamado reproductivo. Es más, el quehacer militar impone en los que "quedan atrás" - el trabajo de abastecer a los ejercitos y proveerles de materiel bélico - es decir, les impone una hiperproducción material. Desde el punto de vista histórico, los

${ }^{15}$ Alatorre, Angeles Mendieta. La mujer en la revolución mexicana. Mexico, DF, IEHRM, 1961, p.173. 
ciudadano-soldados y los ejércitos son productores, pero desde punto de vista material son grandes consumidores. Dado que el quehacer militar consiste precisamente en destruir productos de la labor humana, los ejercitos son hiperconsumidores, son máquinas de consumo voraces $y$ totalmente dependientes en la hiperproducción de los demás. Desde este punto de vista, se podría decir que el espacio militar está caracterizado por improductividad e hiperconsumismo y el espacio civil por reproducción e hiperproducción. Se sugiere un esquema modificado que demuestra no una reproducción de la relación espacio público/hogar, sino un profundo desequilibrio material, social y existencial:

\begin{tabular}{|c|c|}
\hline Espacio militar & Espacio civil \\
\hline hombres/ciudadanos & mujeres/no ciudadanos \\
\hline hiperconsumo & $\begin{array}{l}\text { cludad } \\
\text { hiperproducción }\end{array}$ \\
\hline improductividad & reproducción \\
\hline pelear & trabajar \\
\hline destruir & construir \\
\hline sobrevivir & sobrevivir \\
\hline
\end{tabular}

Tanto la historia narrada como la historia vivida serían muy diferentes si el estado de guerra se entendiera así, y si las esferas militar y doméstico-civil se reconocieran como igual $y$ simultáneamente constitutivas de lo que es el proceso histórico de "la guerra." Tal mudanza de óptica implica una narrativa histórica muy distinta de la convencional. Como sugeriré en seguida, de las dos obras experimentales de Nellie Campobello, la primera, Cartucho (1931), trabaja con el primer esquema esbozado arriba y la segunda, Las manos de mamá (1937), se orienta hacia el segundo.

El estado de guerra también tiene importantes dimensiones sexuales. Al partir al ejército, los hombres-ciudadanos salen de una estructura patriarcal para entrar en otra, la jerarquía militar 
Mi cigarro, mi Singer, y la revolución mexicana

donde de hecho la jerarquía generacional se intensifica. Para las mujeres la ausencia de los padres, hermanos, novios y esposos implica una atenuación de la autoridad patriarcal, en la medida en que esta está impuesta desde fuera y no desde adentro. Esto podría sugerir que la apertura para una revolución sexual sea mayor en la esfera doméstico-civil que en la militar. El soldado pierde la libertad de disponer de su cuerpo y de hasta de su vida mientras para las viudas, esposas y novias abandonadas esta libertad aumenta. Tal dimensión se dramatiza en uno de los relatos más referidos de Cartucho, acerca de la notoria deserción del general villista Tomás Urbina, siempre entendida como una traición a los carrancistas. Lo que realmente pasó, nos dice la narradora de Cartucho, fue otro: a Urbina le llegó la noticia de que en casa su esposa tenía un amante, y además de otra banda villista. Urbina manda fusilar al hombre frente a su casa (la de Urbina). Le llega la noticia que su esposa, presenciando el asesinato, levantó el cadáver del amante, lo metió en la casa y le hizo un velorio - en un cuarto personal de Urbina. Urbina busca vengarse contra la otra banda villista, delito por el cual es ejecutado. O sea, la esposa logra desafiar agresivamente el orden patriarcal en la esfera domestico-civil, pero a Urbina no le es permitido desafiar el orden militar en nombre de sus derechos domésticos.

Sería un error, sin embargo, sugerir que no haya apertura sexual en la esfera militar. Al contrario, la ausencia del orden familiar-reproductivo implica la suspensión de normas de castidad, de prohibiciones contra la violación, el sexo extra-marital, la promiscuidad. En ese sentido el soldado goza de una suerte de impunidad sexual. Se suele condenar rotundamente estas formas de actuar masculinas que reafirman e intensifican la jerarquía de los géneros. Carlos Monsivais, dedicado iconoclasta, es el que se ha atrevido no a negar sino a matizar este juicio. En medio de la violencia y la deshumanizacion, arguye, para muchos actores de ambos sexos esta situación de impunidad sexual habrá significado también el descubrimiento del cuerpo y del placer, el nacimiento 
de una idea de libertad - y liberación - sexual, la incorporación de la sexualidad y la sensualidad en el concepto del sujeto y de la ciudadanía. Para Monsiváis la más radical historia de emancipación sexual en la revolución - la de la homosexualidad es casi inescribible. Apenas se discierne a través e la homosocialidad y el homoerotismo de los textos. ${ }^{16}$ Dentro del marco heterosexual, Campobello en Las manos de mamá tematiza precisamente esta dimensión de autonomía sensual y libertad sexual durante la revolución.

\section{Cartucho: Relatos de la lucha en el norte (1931)}

El relato del General Urbina ejemplifica el propósito declarado de Cartucho: corregir las mentiras y distorciones sobre el villismo diseminadas por la historia oficial post-revolucionaria. Hay mucho que comentar sobre este texto, y me enfocaré aquí sólo en los tres temas mencionados arriba: 1) la búsqueda de formas alternativas de historicidad, 2) el desarrollo de una perspectiva feminocentrica sobre la revolución y 3) la revolución como revolución sexual.

1. Historicidad. Como sugiere su subtítulo ("relatos"), Cartucho narra desde la Memoria y contra la Historia, creación mentirosa de "los curros" - gente urbana, de fuera. Adopta una forma de narrar que es intensamente temporal, sin ser ni cronológica ni, aspecto importante, teleológica. El texto consiste de 55 breves capítulos sueltos. Algunos son retratos de personajes, otros muchos evocan con vividez magistral a algún individuo para luego describir en términos igual de vívidos la manera de su muerte. Otros cuentan anecedotas. $\mathrm{Ni}$ una sola fecha caléndrica aparece en todo el texto. Un par de frases del relato del General Urbina ejemplifican el estilo narrativo:

${ }^{16}$ Es un aspecto interesante de la obra de Martín Luís Guzmán, por ejemplo. Me refiero sobre todo al Aguila y la serpiente (1928), sobre todos los primeros capítulos y el famoso encuentro con Pancho Villa, y a una escenas claves de $A$ la sombra del caudillo (1929). 
Mi cigarro, mi Singer, y la revolución mexicana

Tres personas lo relatan. Pasaron las fuerzas de Rodolfo Fierro, rumbo a las Nieves entre las seis de la tarde y diez de la noche. ¿Qué día? ¿Qué mes? ¿Qué año? Todos iban muy apurados y hablaban en voz baja. Acabando de llegar fusilaron al chofer de Fierro... (948)

Aquí se observan varias características claves de Cartucho: la veracidad yace en testigos (no documentos); la historia yace en relatos orales; el tiempo caléndrico no importa, pero el horario del dia sí; la verisimilitud yace en detalles sensoriales como las voces en la noche, el movimiento apurado. Con una intervención directa - "¿Qué día? ¿Qué mes? ¿Qué año? - la narradora distingue su discurso explicitamente de la norma historiográfica.

La revolución aparece, tanto en Cartucho como en Las manos de mamá, menos como un proceso histórico que como un conjunto, hipotéticamente completo, de relatos y memorias. Es a eso que me refiero al caracterizar los textos como no-teleológicos. Aunque Campobello toda su vida se identificaba como producto, beneficiaria y partidaria fanática de la revolución ${ }^{17}$, en sus escritos la revolución no pervive en el presente en forma de resultados, ni en el pasado en forma de ideales o esperanzas. Existe en el "puro cuento." Esta óptica no-teleológica le evita a Campobello el pesimismo que permea del resto del corpus narrativo de la revolución, donde se evalua la revolución con relación a esperanzas no cumplidas o ideales co-optados.

2. Perspectiva feminocéntrica. Cartucho conserva el mapa androcéntrico de la sociedad en guerra esbozado en la figura 1. El texto está lleno de mujeres, pero como actores aparecen sobre todo en papeles de apoyo y en sus relaciones de madres, esposas, etc. Aparecen a menudo al final de las anécdotas recuperando cadáveres, rezando a los desaparecidos, curando heridos o

${ }^{17}$ GonzÁlez, Manuel Pedro. Trayectoria de la novela en México. México, Ediciones Botas, 1951, p.289 citado por PARRA, Max. Perspectivas subalternas en Cartucho de Nellie Campobello. Manuscrito en prensa, 1997. 
llorando muertos. Aunque se subraya la importancia de estas actividades, las mujeres nunca son el personaje principal de la narración. Por otro lado, sí se comunica muy claramente la compenetración de los mundos militares y civiles en la revolución. Pero donde Campobello realmente abre terreno nuevo es en el uso de mujeres y niños - los no-ciudadanos - como testigos, además testigos privilegiados precisamente por su posición afuera de la hierarquía militar y de la Historia (es decir de los órdenes ciudadanos). La innovación más visible y más comentada de Cartucho es el hecho de que la autoridad narrativa en el texto es una niña, basada en la niñez de Campobello en Chihuahua durante los altos años del villismo. El texto se nos presenta como una reconstrucción adulta de memorias infantiles de una niña. Estas incluyen memorias de experiencias propias de la narradora, $\mathrm{y}$ de relatos que le fueron contados por otros, sobre todo su madre. Aunque los ciudadanos-soldados siguen siendo los productores de la Historia, entendida como una serie de actos y hechos, los no-ciudadanos en Cartucho - es decir, la niña y las mujeres - son co-productoras de la Historia entendida como el relato público de los hechos. Así Campobello les abre un espacio de ciudadanía que se ampliará aún más en Las manos de mamá.

Contra la autoridad interesada (urbana, clasista) de la historia oficial, Campobello opone estrategicamente la ingenuidad y candor de la memoria infantil. El gesto es transparente, pero su ejecución es bastante compleja a nivel epistemológico y estético. Por ejemplo, aparece un código alternativo de verosimilitud basada en descripciones detalladas, impasivas y estetizadas de la destrucción física de los cuerpos por la guerra, descripciones que violan el pudor de la narrativa oficial. Aunque muchos lectores aprecian profundamente la fuerza expresiva de este procedimiento, también ha provocado reacciones fuertes, como el ataque de normatividad que manifestó el crítico Manuel Pedro González en 1951: 
Mi cigarro, mi Singer, y la revolución mexicana

La nota mas sobresaliente y desconcertante de estas historias de Nellie Camponbello es la insensibilidad - real o fingida - de la autora frente a los horrores que pinta. Es este un aspecto poco menos que repugnante por lo inhumano y terrible. El niño normal no reacciona en esta forma ante la sangre y la muerte, maxime tratándose de niñas - como en este caso - mas propicias por lo general a las reacciones conmiserativas o cuando menos de miedo y de horror. (15)

González caracteriza la visión de Cartucho como "inhumana", pero mi argumento sería el contrario: al sacar a los muertos, y las muertes, del anonimato, la masificación, y la objetividad, y al enfocar la muerte como experiencia personal y como proceso vital, Campobello termina humanizando intensamente el quehacer guerrero y nivelando la jerarquía militar. Esta intervención humanizante y democratizante es el producto de la óptica privilegiada de las no-ciudadanas en su papel de testigos.

3. La revolución sexual. Ironicamente, Manuel Pedro González tiene perfectamente razón cuando observa que la niña-narradora de Cartucho no es "normal". La "anormalidad" de la niña se debe en parte al hecho de que el orden patriarcal no se está reproduciendo en ella de manera "normal," es decir en forma de la represión, la auto-subordinación, el ajenamiento de su proprio deseo. El texto exhibe no una ausencia de "reacciones conmiserativas ...miedo y de horror" (esa es una mala lectura por parte del crítico) sino la coexistencia de estas reacciones con otras "normalmente" prohibidas en las niñas - la curiosidad, la crueldad, la burla, el egocentrismo, la indiferencia. La esposa del General Urbina tampoco se comportó como esposa "normal".

\section{Las manos de mamá (1937)}

En Cartucho el espacio doméstico-civil es un sitio privilegiado desde donde testiguar los hechos de la revolución, pero el quehacer histórico permanence en la esfera militar. En Las manos de mamá el espacio doméstico-civil es el sitio de la 
narración y de lo narrado. Es decir en este segundo texto, Campobello lleva otro paso más hacía una óptica feminocéntrica, buscando representar no como la revolución se veía desde el espacio doméstico-civil, sino como se vivía. Hace una intervención deliberada en los paradigmas de género y ciudadanía que la revolución oficial dejaba sin revolucionar. Detrás de Las manos hay una preocupación por ampliar las pautas de la ciudadanía - y de la literatura nacional - con relación a las mujeres. De hecho, Campobello inició el texto durante una estancia en Morelia donde, ya como directora de la Escuela Nacional de Danza, fue obligada a participar en un espectáculo patriótico cuyo nacionalismo fácil y superficial le repugnaba. Comentó el asunto en un lenguaje muy marcado por el género:

Amar el pueblo no es solo gritar con él en fiestas patrias, ni hacer gala de hombría besando una calavera de azucar, ni rayar un caballo, ni deglutir de un sorbo media botella de tequila. Amar a nuestro pueble es enseñarle el abecedario, orientarle hacia las cosas bellas, por ejemplo hacia el respeto a la vida, a su propia vida y claro está a la vida de los demás, enseñarles cuáles son sus derechos y cómo conquistar estos derechos. ${ }^{18}$

Las manos de mamá narra la historia de una joven madre norteña viviendo y sobreviviendo el tumulto de la revolución, en la cual su esposo pierde la vida. Como Cartucho, es de fuerte carácter autobiográfico, y está narrado en primera persona por una niña, pero esta vez el enfoque de la narrativa es la madre y la vida familiar. La madre sale como un personaje inolvidable $e$ idealizado. Aparece en los papeles reproductores de las que "quedan atrás"- madre dedicada y abnegada, viuda enlutada, enfermera valiente, sostenta del hogar. También aparece en los papeles de sustitución al hombre, de ciudadana, en fin: proveedor

${ }^{18}$ Del prólogo a Mis libros (1960), citado en MEYER, D. Nellie Campobello's Las manos de mamá... Op. cit., p.748. 
Mi cigarro, mi Singer, y la revolución mexicana

y jefe de familia, actor jurídico y político, productor $e$ hiperproductor. El título mismo del texto tematiza el trabajo y la productividad, poetizados en la evocación lírica con la que se abre el texto: "sus manos [que] en el trabajo, se apretaban sobre las espigas doradas y formaban ramilletes que se volvían tortillas húmedas de lágrimas" (971). En contraste con la imagen de la mujer que espera, la madre se caracteriza por una mobilidad constante. El texto está marcado por sus idas y venidas, sus pasajes de una actividad para otra. "Se levantaba temprano, se iba; caminaba mucho" (974a); "Entraba a la casa, se desanudaba el pelo, cantaba, iba y venía...Removía aquí, allá" (974b). Esta movilidad dramatiza la autonomía y el poder de actuar de la madre. Es dueña de su cuerpo.

La mamá también aparece en papeles que no aparecen en ninguno de los dos esquemas. Más notablemente, aparece como sujeto del placer, como actor/agente sensual, sexual, contemplativa, cultivadora de sus apetitos. Tiene amigos y amantes. Através del texto nacen una serie de niños de paternidad varia e indefinida. Canta, baila, coquetea:

Frente a la Plaza de la Lilas,... está ella y tres voces de hombres que se oyen. Canto sentimental en noche oscura, rendijas de luces anémicas, un fuerte perfume que no tiene razon de ser... (985a)

Y fuma. Le encanta fumar. Una de las imagenes centrales de la madre como sujeto de su propio placer es la de ella sentada de noche en la puerta de la casa, fumando un cigarro: "Daba fumadas y fumadas y casi entrecerraba los ojos. Entonces nosotros no le hacíamos ruido" (974b). A sus hijos les encanta: "La lumbre de su cigarro podía ser una tortilla entre sus dedos, pero era la luz que, como nuestra vida, se adhería a sus manos" (974b-975a). La sensualidad amplia y polimorfa de la madre, dimensión absolutamente censurada por todos los paradigmas de la maternidad y de ciudadanía, es identificada por la hija como un 
eje central del ser y del quehacer de su madre, y de su sobrevivencia en el estado de guerra. Más importante todavía, la narradora ve la sensualidad como dimensión clave y absolutamente natural de si misma. En ese sentido, la revolución sexual se realiza más que todo en la niña.

Se propone, entonces, que la propuesta literaria, estética, existencial e histórica de Campobello es crear una imagen de las otras revoluciónes mexicanas, paralelas a la primera, relacionadas a ella, pero regidas por ritmos e impulsos proprios. El proyecto implica notables innovaciones estéticas e epistemológicas. Por ejemplo, dado que el centro de gravedad narrativo de Las manos está en la esfera doméstica civil, la esfera militar se recupera desde allí, invirtiendo las relaciones convencionales de "escena" y "fuera de escena". Se puede identificar una seria de intervenciones epistemológicas por las cuales Campobello efectua esta inversión:

1. Universos paralelos. Las esferas doméstico-civil y militar se presentan como universos paralelos, compenetrados pero distinguibles y equivalentes, con códigos y estéticos propios: "Allî teníamos lo nuestro: Mamá, la sierra, los ríos, los soldados en sus caballos; las banderas danzando en sus manos y Mamá llevando sus cabellos negros a la luz del sol" (976a). Por un lado los soldados con banderas y por otro Mamá con su pelo. La imagen simultaneamente afirma la compenetración de las dos esferas en la experiencia de los niños, y la absoluta autonomía de la madre con respeto a la esfera militar. El pasaje contradice explicitamente el contrato sexual que define las mujeres unicamente con relación a los hombres.

2. Metamaternidad. La relación entre Mamá y la esfera militar en Las manos muy a menudo se expresa como una relación materna que infantiliza a los soldados y subordina lo militar a los valores del hogar. Dice la narradora infantil: "Ellos [los soldados] eran más niños y mejores [que nosotros]; daban su vida sonriendo y no pedían nada; nosotros no dábamos nada y lo recibíamos todo" (977a). Criticada por ayudar a soldados de bandas rivales, la madre insiste que: "son mis hermanos... son como niños que 
Mi cigarro, mi Singer, y la revolución mexicana

necesitaron de mi" (980a). Los valores del hogar son explicitamente anti-bélicos.

3. Feminización. Al entrar en la esfera doméstico-civil, los soldados se feminizan. El soldado-amante, Rafael Galán, por ejemplo, llega a casa de mamá sin rifle, su forja a la mano, y más tarde un ramo de nardos (982b). Respetuoso y formal, pasa una noche con mamá fumando y conversando antes de encontrar su muerte en un ataque al alba. Se le identifica como romántico y como lunar:

Rafael Galán, nardos, pedazos de luna, sentado en la puerta gris, ante una mujer, le narra toda su vida... Capitán: fue usted un gentilhombre con mi madre. Los nardos y las noches de luna son de usted (982b-983a).

La autonomía de la esfera doméstico-civil se afirma a través de una serie de imágenes claves que transforman - o revolucionan - algunos de los símbolos más canónicos de la revolución mexicana. El cigarro, por ejemplo, se establece como contraimagen del rifle - Mamá lleva aquel a la mano como los soldados llevan este. Ambos queman y lucen, pero el rifle "deshace" las vidas y causa dolor mientras el cigarro está asociado con la recuperación, el descanso, el placer. La máquina Singer aparece como contraparte de la máquina más identificada con la revolución, el tren. Este en Las manos está asociado con la muerte. Los rieles de tranvía frenta a la casa echa "reflejos largos en forma de puñales y haciendo una mueca" (975b). Cuando viajan en tren para rescatar a un hijo herido en el frente, el tren salta de los rieles y mama y su hija apenas salen con vida. ${ }^{19} \mathrm{La}$ máquina Singer se introduce por su "canto de fierros", el sonido rítmico que la asocia con el ferrocarril. Pero es una máquina que construye y no destruye, una máquina que no somete a las

${ }^{19}$ La asociación del tren con la muerte se establece desde el inicio del texto, cuya evocación onírica lamenta que la madre "pasó por el puente de piedra hasta llegar junto al tren. Se fue... No volverá mas" (972). 
personas sino que canta en dúo con ellas: "Ella cantando al ritmo de la máquina; la máquina, una niña de acero entre sus manos, dejándose llevar por ellos" (983a). Y sobre todo, a contraste de la máquina que lleva a la gente hacia la muerte, la Singer esta construida para ser llevada. Acompaña la familia siempre hacia la vida. Cuando muere el padre, "Mamá desarmó la máquina en que cosía nuestras tuniquitas, amarró los principales tornillos en un trapo y los guardó" (977a).

La mención de las piezas sueltas de la Singer toca una dimensión importante en la historia de esta máquina. Su distribución masiva dependía del hecho de que fue fabricada con piezas reemplazables. En la historia de la tecnología industrial, fue el segundo aparato mecánico con esta característica. El primero? - el rifle. La Singer también comparte historia con el otro talismán de mama, el cigarro. Según la historiadora Carmen Ramos Escandón, las industrias cigarreras y costureras en México fueron las que tuvieron más alta participación de trabajo asalariado femenino, empezando bajo el profiriato. Contingentemente, fueron los primeros núcleos de mobilizacion laboral especificamente femenina. ${ }^{20}$ Supiéralo o no Campobello, el conjunto de imágenes que arma - el cigarro, el rifle, la Singer y el tren - lleva una fuerte carga histórica.

\section{Género y ciudadanía}

La máquina Singer ilumina el episodio reconocido como el más críptico de Las manos. Se trata de una confrontación legal donde se pone en juego precisamente la ciudadanía de Mamá, como amante y como madre. El episodio se narra de manera indescifrable. Durante un tiempo por circunstancias no explicadas, Mamá se ve obligada a dejar a sus hijos con la familia de su marido muerto. Cuando aparece para recuperarlos, se lo

${ }^{20}$ RAMOS, Carmen. Mujeres mexicanas: historia e imagen del profiriato a la revolución. Revista Encuentro, El Colegio de Jalismo, 4:3, 1997, pp.41-57. 
Mi cigarro, mi Singer, y la revolución mexicana

prohiben, y ella los lleva a la fuerza. La demandan en la corte y la noche antes de la audiencia, su consejera le dice, "sólo Dios podrá salvarte." Reflexionando sobre su situación, Mamá concluye: "Mi salvación la tenía Dios; entonces comprendí que estaba en mi mano" (978b). Toma su blusa y la rompe. A la mañana siguiente aparece delante del juez con "mi hija de un año" en brazos. Entre un coro de críticas y acusaciones, e insistiendo que "mis hijos son míos," muestra al juez la blusa rota. Éste declara "Este es el delito. ... Sus hijos son suyos." ¿Qué pasa aquí? Debemos la aclaración a la agudeza de las críticas Doris Meyer y Irene Matthews. ${ }^{21}$ La "hija de un año" es obviamente un hijo ilegítimo cuya apariencia significa para la familia paterna el derecho de quitarle a Mamá sus hijos legítimos. La blusa rota es la prueba (falsa) de que el embarazo fue el resultado de una violación, a cuya víctima no se puede culpar. De allí la conclusión de Mamá, que:

Así es la ley. ...A veces dice que los hijos nacidos de la propia carne no son nuestros, pero una rotura hecha a tiempo en la blusa desbarata las ochocientas hojas donde lo afirman. (979a)

Como parábola de la ciudadanía femenina, el episodio es insuperable. Si las leyes están construidas según los intereses de los hombres, ¿qué puede hacer una mujer para defenderse de, o por, la ley? ¿En qué consiste la ciudadanía de las mujeres, de las madres? La conclusión formulada por Mamá enfatiza la pura irracionalidad de la ley con relación a la mujer y a su cuerpo, en comparación con su supuesta racionalidad con respecto a los hombres-ciudadanos. Tecnicamente, mamá está enfrentando la asimetría de las leyes que tratan de manera totalmente distinta y desigual. la maternidad y la paternidad ilegítimas, es decir, la conducta sexual masculina y femenina. La frase "mis hijos son míos" tiene estatus y fuerza legal en la boca de un hombre, pero

${ }^{21}$ MEYER, D. Nellie Campobello's Las manos de mamá... Op. cit.; MATTHEWS, I. Mothering in war... Op. cit. 
no en la de una mujer. En boca de una madre soltera, articulan derechos e intereses no protegidos sino amenazados por la ley. La mamá recuerda unos consejos de su padre: "Hay que estar dentro de la ley para defenderse. Los tinterillos, los huizacheros, son gente muy técnica" (978b). Pero ella no puede entrar en la ley por las mismas puertas que los ciudadanos masculinos. Por la mentira de la blusa, logra colocarse "dentro de la ley de los hombres" asumiendo una de las identidades legales y sexuales que la ley patriarcal le permite, la de mujer violada. Relatando el episodio después a un amigo, la mamá presenta el universo legal como totalmente ajeno a su cosmos normal donde se costuran blusas en vez de romperlas.

\section{"Una auténtica batalla por la forma"}

Las manos de mamá, señala Kemy Oyarzún, exhibe "una auténtica batalla por la forma". ¿QQué opciones literarias tenía Campobello para narrar su revolución? Precisamente por la asimetría entre los géneros con relación a la actuación histórica, no existe una novelística histórica feminocéntrica (excepto en los reinos no realistas del romance y la ciencia-ficción, donde prolifera), ni puede existir mientras lo que viven y hacen las mujeres queda al margen de la Historia. Campobello armó su batalla por la forma al eligir no escribir ni novela ni autobiografía ni memoria. Rechazó todas las variedades de autoridad narrativa monológica para experimentar con una autoridad narrativa dispersa como la memoria. En este aspecto, ella es una precursora importante, y no reconocida, del Juan Rulfo de Pedro Páramo, del Agustín Yañez de Al filo del agua, del Carlos Fuentes de La region más transparente, de la Elena Garro de Recuerdos del porvenir. Aquí el espacio me permite enfocar sólo dos aspectos del experimentalismo narrativo de Las manos. el uso de una protagonista doble y una voz narrativa transgeneracional.

22 OYARZÚN, K. Identidad femenina, genealogía mitica, historia... Op. cit., p.189. 
Mi cigarro, mi Singer, y la revolución mexicana

Protagonista doble. El relato tiene un doble centro. Tanto la madre como la hija son protagonistas; el texto es simultaneamente una autobiografía de esta y una biografía de aquella, y lo que se narra adquiere significados distintos en relación a cada una de ellas. Desde la madre, lo que se narra es "una vida deshecha por los estragos de los rifles" - viudez prematura, mudanzas repentinas; escaseces de todo tipo; hijos heridos y muertos; amigos y amantes que vienen y no vuelven más; instituciones sociales y judiciales intermitentes y opacas; peleas con la familia del compañero muerto. Desde la niña, por contraste, se narra "una vida que se hace", una niñez de felicidad y plenitud, saturada de juegos, salud, amor y sobre toda una intensa pasión por la madre. Creo que la crítica Irene Mathews tiene razón al interpretar este doble protagonismo en términos del contraste psicoanalítico entre la identidad femenina, definida por la relacionalidad, e identidad masculina, definida por la separación. ${ }^{23}$ Campobello busca y crea una manera de narrar desde la relacionalidad entre hija y madre y entre presente y pasado. De ahí su creación de una voz narrativa elástica, metamorfoseante, que no busca separarse de lo narrado sino integrarse a ello.

Voz narrativa trasngeneracional. A pesar de la narración en primera persona la secuencia narrativa no se elabora desde un punto de vista consistente. El texto es narrado por la hija adulta del personaje titular, pero esta narradora adulta a menudo $e$ imprevisiblemente se desdobla para narrar desde la óptica de la hija en su niñez. Este desdoblamiento, sugiero, crea la forma peculiar que toma la historicidad en la obra. El pasado vive simultánea $e$ indistinguiblemente en el pasado y el presente. Todos seguimos siendo siempre, entre otras cosas, el niño o la niña que fuimos. Y lo que nos contaron en la niñez pervive en nosotros simultaneamente como memoria adulta y memoria

${ }^{23}$ Meyers y Mathews citan las teorías psicoanalíticas feministas (sobre todo las de Nancy Chodorow sobre la evolución de la identidad relacional femenina) para analizar la relación madre-hija en el texto. 
infantil. ${ }^{24}$ Las siguientes lineas ejemplifican la manera en que el texto evoca un doble escala de valores al reconstruir la experiencia infantil desde la madurez:

Nosotros desconocíamos la tristeza. Todo era natural en nuestro mundo, en nuestro, juego. La risa, las tortillas de harina, el café sin leche, las caídas y descalabradas, los muertos las descargas de los rifles, los heridos, los hombres que pasaban corriendo en sus caballos, los gritos de los soldados, las banderas mugrosas, las noches sin estrellas, las lunas o el mediodía; todo, todo era nuestro; porque esa era nuestra vida. (976a)

Al mismo tiempo que autoriza la perspectiva de la niña, el texto anticipa e impone otro juicio: "No es para nada natural que las cosas sean así". Se desdobla el lector: el catálogo es coherente desde la niña y dispareja desde lo adulto, y ambos tienen razón. La narradora adulta crea una óptica dual - la de la madre viviendo perdida, arriesgada, voluntariosa, y la de la hija viviendo las mismas circunstancias como continuidad y la plenitud. Es esencial para el proyecto de Campobello que esta óptida dual no se resuelva en una versión coherente o una voz narrativa consistente. Es decir, que no se resuelva en Historia. Aunque puede ser demasiado formuláica la conclusión, diría que Campobello interviene al nivel de la temporalidad para crear un sentido relacional de la historicidad que revoluciona la Historia, en su sentido canónico.

El desplazamiento de la autoridad narrativa en la niña es esencial a la óptica histórica de Las manos. El texto aprovecha las características que casi siempre distinguen los narradores infantiles. La niña no vive dentro de la moralidad burguesa, y no distingue entre la conducta transgresiva y normativa de su madre. La conducta transgresiva se vuelve "narrable." Segunda, es una

${ }^{24}$ Los primeros capítulos de Las manos evocan las memorias infantiles de la madre, dándo al relato un alcance histórico de cuatro generaciones. 
Mi cigarro, mi Singer, y la revolución mexicana

narradora muy inexperta que produce un relato altamente desordenado (aspecto no siempre visto como positivo por los lectores). Los episodios se narran al azar o de manera asociativa; la cronología y la causalidad son ocasionales, pero sobran historicidad y verosimilitud.

\section{La danza ciudadana en tiempos de guerra}

Este desorden formal mimetiza el desorden existencial de la vida civil en estado de guerra. La madre vive de un dia para otro, respondiendo a circunstancias muy inestables que ni controla ni preve. Este desorden apunta hacia lo que, segun mi parecer, constituye los dos ejes existenciales de la obra: la interrupción y la improvisación, palabras que captan por un lado la forma de actuar que el estado de guerra le impone a la madre, y por otro, la forma de lectura que el texto impone al lector. La madre tiene que improvisar la estabilidad y coherencia de la unidad familiar en el contexto de interrupciones y descontinuidades constantes. El lector debe improvisar la unidad, coherencia, causalidad y cronología del texto a base de condiciones que varian de un capítulo para otro. A ninguno de los dos le es permitido cumplir plenamente con su tarea. Cuando el pretendiente Rafael Galán muere, la forma novelística misma está "deshecha por los rifles" (982). El movimiento errático, improvisado, el ir y venir (989a) de mamá y su familia recuerda y hace eco de las narrativas militares de la revolución mexicana. Estas presentan las bandas revolucionarias errando interminablemente por el paisaje nacional sin rumbo, en busca de enemigos, de nuevos jefes, de escondidos. En las narrativas militares, el carácter errante e improvisado del movimiento suele tener un significado negativo dictado por la historiografía teleológica. La falta de rumbo, de destino fijo, de proyecciones al futuro, de relaciones de lealtad estables, significa precisamente la falta de una teleología, la falla de la revolución como proceso de cambio histórico. 
En Las manos, sin embargo, el significado es otro. Los movimientos de la familia, las constantes idas y venidas de la madre, las separaciones y reuniones no se presentan como arbitrarios o carentes de sentido. Son cargados de significado, de propósito, y sobre todo de belleza. De ahí la hipótesis que, si el principio existencial de Las manos es la improvisación, su principio estético es el que dominó la vida entera de Nelly Campobello: el de la danza. "Mamá, dance para mi", dice la narradora en la invocación al texto,

cante, deme su voz. ...Quiero adorar las puntas de sus dedos. Quiero verla bordar ante mi su danza eterna. Mamá, vuelva su cabeza. Sonría como entonces, girando en el viento como amapola roja que se va deshojando. (974b)

Precisamente por la imposición de la historia, la danza que ejecuta y encabeza la mamá es improvisada e interrumpida. Detrás hay otra imagen de lo que debería ser la vida: una danza ritual o coreografiada. Por un lado, el estado de guerra elimina las condiciones básicas para la danza coreografiada o formuláica: escenario y personal estables, control del tiempo y del tempo, posibilidad de repetición, co-presencia de la pareja heterosexual de danzantes principales. Pero no elimina el ritmo, la gracia, la posibilidad de movimientos cargados de harmonía, sentido $e$ intencionalidad. Al mismo tiempo, la revolución crea las condiciones para la danza improvisada: suspensión de códigos normativos, renovación constante del escenario, autonomía de la mujer-danzante con respecto a su cuerpo y sus movimientos, necesidad/posibilidad de actuar de manera espontánea y experimental con relación al espacio y a los otros danzantes según aparecen en el escenario.

De Campobello el famoso periodista mexicano Fernando Benítez dijo en 1934, 
Mi cigarro, mi Singer, y la revolución mexicana

Nellie posee una segunda naturaleza rítmica, un certero instinto que la lleva a descifrar la mímica del baile y a comprender su velado sentido, una ternura y un amor que la hacen sentir nuestras danzas e interpretarlas como ninguna artista las ha interpretado y sentado. ${ }^{25}$

Por la estética de la danza improvisada, entendida en relación negativa con la danza ritual o coreografiada, Las manos plantea la historicidad de la revolucion mexicana y el impacto del estado de guerra en el proceso vital de las personas. De esa forma, sugiero, el texto de Campobello registra las "otras revoluciónes" de 1910-1930: la existencial, la doméstica, la familiar, la espacial y la sexual. El núcleo de su proyecto literario consiste en evocar estas otras revoluciones al corazón del proceso nacional-histórico y no como "fuera de escena."

\section{Muralismo y el ballet de masas}

Curiosamente, en términos estéticos, el proyecto dancísticoliterario de Las manos parece ir en contrasentido al proyecto muralista-dancístico que desarrolló Campobello en su famoso Ballet de la Ciudad de México - proyecto igual de olvidado. Si Las manos de mamá registra el impacto de la danza en práctica literaria de Campbello, su creación dancística demuestra una interacción transmediática con otra forma artística fundamental en la época posrevolucionaria: el muralismo.

En los años 20, con la fundacion de la SEP bajo Vasconcelos, se adoptó una política estatal sobre la danza, no como forma de expresión artística, sino como medio de formación de identidades y de conciencia. Las Misiones Culturales establecidas por Vasconcelos con el fin de educar a las comunidades indigenas y campesinas para integrarles a la vida nacional y difundir los principios revolucionarios, frecuentemente incluían especialistas de danza. Los programas de las escuelas

${ }^{25}$ Citado en Dallal, A. La danza en México en el siglo XX. Op. cit., p.102. 
rurales incluian danza regional. A los misioneros también se les encargó la recuperación de danzas tradicionales, un trabajo que los historiadores de danza en Mexico consideran "de enorme importancia". ${ }^{26}$

En 1930 las bailarinas Nellie y Gloria Campobello regresaron a Mexico después de una estancia existosísima en Cuba, ya listas para lanzarse profesionalmente en su tierra natal. Nellie ya tenía fama literaria. Su poemario Yo, publicado en Cuba, había atraido la atención hasta de García Lorca, Langston Hughes, y Lizst Arzubide. Las hermanas entraron como maestras en la SEP y en la seccion de musica y baile del departamento de Bellas Artes. No existía una companía nacional de danza, ni una escuela nacional de danza.

Trabajabamos [dijo Nellie] dentro de un marco purmaente escolar y sin la menor pretension de ir a un profesionalismo. Nos ofreció danzar en las escuelas y en las colonias pobres asi como contibuir en actos oficiales o politicos y crear espectáculos escolares en los estadios. ${ }^{27}$

Esta última referencia, a los espectáculos en los estadios, deja vislumbrar los paralelos con el muralismo. Tanto en la pintura como la danza, se legislaba la búsqueda de formas artístias adaptadas a espacios públicos, y a públicos masivos. A los bailarines se les ofrecía espacios en actos oficiales y estadios, como a los pintores se les ofrecían los muros de edificios públicos, igual que, dice la Enciclopedia de México, a los campesinos se les ofrecían parcelas de tierra. En 1923 se presentó un ballet titulado

${ }^{26}$ Dallal, A. La danza en México en el siglo XX. Op. cit. Sobre la historia de la danza mexicana ver también QuIROZ, M. T. Danza y poder. Op. cit.; MoRALES, María Alejandrina Escudero. Zapatillas y recuerdos: la historia oral, una fuente para la historia contemporanea de la danza en México. Tesis de licenciatura, Filosofia y letras, UNAM, 1999; Aproximación a la danza. Tierra Adentro, número especial, marzo de 1999.

${ }^{27}$ MATTHEWS, I. Mothering in war... Op. cit., p.71. 
Mi cigarro, mi Singer, y la revolución mexicana

Quetzalcoatl en el patio de la SEP, espacio cuyos muros se acababan de regalar a Diego Rivera como espacio muralístico. ${ }^{28}$

En ambos medios, danza y pintura, se trataba de desarrollar una estética panorámica, inclusiva y de escala monumental. Esta búsqueda implicó otra lucha por la forma, un experimentalismo constante. Por ejemplo, en 1922, el mismo año (o casi) que Roberto Montenegro pintó uno de los primeros murales, La Fiesta de la Santa Cruz (es decir, con un tema dancístico), se organizó una "noche mexicana" de baile en el Bosque de Chapultepec:

Los espacios del bosque se llenaron de minúsculos escenarios decorados segun los cánones del arte populara mexicano en donde se bailaron las danzas regionales. [y] en el centro del lago, la primera bailarina Cristina Pereda interpretó un ballet con tema nacional. ${ }^{29}$

En ambos medios se trataba de recuperar prácticas autóctonas (danzas, música, técnica de fresco), diseminar imágenes visuales de los indígenas, plantear temas nacionales y nacionalistas y crear formas de arte asequibles a números masivos de espectadores.

Hoy día detrás de estos proyectos de recuperación solemos identificar procesos de reconversión. El término denomina un proceso histórico-cultural que saca formas expresivas de un contexto y los reinserta en otro. En este caso, se trata de la reconversión de danzas rituales y populares en danza teatral o de concierto, lo que significa también la reconversión de capital cultural rural y regional en capital cultural urbano y nacional. Tales reconversiones no dejan intacta la forma original, ni en el nuevo contexto, ni tampoco en el contexto de orígen. Las misiones culturales estaban encargadas también de orientar las artes populares en las comunidades, enseñándoles, por ejemplo, a participar en festivales artísticos dentro de un marco nacional.

${ }^{28}$ Dallal, A. La danza en México en el siglo XX. Op. cit., p.111.

${ }^{29}$ Dallal, A. La danza en México en el siglo XX. Op. cit., p.111. 
Mary Louise Pratt

Ya para 1930 se había consolidado la presión para sacar la danza del ámbito educativo y armar un proyecto nacional dancístico profesional. In 1932 el nuevo Consejo de Bellas Artes inauguró la primera Escuela Nacional de Danza, siguiendo el modelo de las Escuelas de Musica y de Pintura, y a base de dos propuestas: una de Nellie y Gloria Campobello, y otra de Carlos Mérida, pintor reconocido entre los fundadores del movimiento muralista. Merida, miembro de la Liga de Artistas y Escritores Revolucionarios, fue un promotor incansable de proyectos nacionales de danza a través de los años 20 y $30 .{ }^{30}$ Las hermanas Campobello contaban entre sus colaboradores dos figuras gigantescas en el mundo de las artes: el escritor Martín Luis Guzmán y José Clemente Orozco. Ambos se involucraron profundamente con el trabajo de la Escuela Nacional de Danza, encabezada por Nellie Campobello a partir de 1937 (año de publicación de Las manos) y de su compañía, el Ballet de la Ciudad de Mexico. Se trata no solo de una interacción entre pesonas, sino también una interacción transmediática entre proyectos, prácticas y procesos estéticos. Si Las manos incorpora la danza a la literatura, la coarticulación entre danza y muralismo se reflejaba claramente en una tipo de espectáculo muy apreciado en la época y ahora practicamente olvidada: el ballet de masas.

\section{El ballet de masas}

El ballet de masas era un tipo de espectáculo dancístico masivo, adaptado especialmente para los estadios, que combinaba bailarines y coreografía profesionales con participantes no profesionales. Practicamente todas las grandes bailarinas y coreógrafas de los 30 y 40 participaron en esta forma de creación. Para dar un ejemplo, uno de los primeros y más elogiados ballets de masas fue una obra de Nellie Campobello titulado El 30-30, o Ballet Simbólico Proletario 30-30 que estrenó en el Estadio

${ }^{30}$ Quiroz, M. T. Danza y poder. Op. cit., pp.69, 100. 
Mi cigarro, mi Singer, y la revolución mexicana

Nacional en 1931. El título alude al rifle 30-30 tan usado durante la revolución. El ballet representaba el triunfo de la revolución en 3 cuadras (se nota el término visual): revolucion, siembra y liberacion. El cuerpo de baile incluía 400 mujeres vestidas de rojo; 200 sembradoras; 200 campesinos y 200 obreros. El impacto de la obra, sin duda en parte por la novedad, fue muy fuerte. "Tuvo un movimiento extraordinario, muy ritmico y no obstante lo hondamente expresivo, de una sencillez absoluta" dijo un crítico. Otra reseña lo califica de

una verdadera obra de arte de inestimable valor por su alta expresion simbolica, por la fuerza de su objetivo revolucionario ....algo de lo mas bello y significativo que se ha presentado en los escenarios de nuestros teatros. ${ }^{31}$

Las hermanas Campobello coreografiaron juntas el ballet de masas Tierra con 3000 danzantes, sobre el tema de la revolucion agricola. Su última contribución al género parece ser un ballet de masas titulado Aleluya, en honor a Miguel Alemán en 1946. Otra bailarina y coreógrafa destacadísima de la época fue la norteamericana Waldeen, invitada en 1939 por el pintor Mérida a formar una escuela de danza moderna mexicana. Muy dedicada al proyecto revolucionario, Waldeen triunfó en 1940 con su ballet de masas La Coronela 1940, visto como un parte de aguas por su combinación de danza moderna con el tema nacionalista. ${ }^{32}$ Waldeen también montó la obra Siembra con 5 mil participantes. $\mathrm{Su}$ discípula Guillermina Bravo, hoy todavía una fuerza protagónica en la danza mexicana, montó otro ballet de masas en 1949, titulado Fuerza matriz. Diez años más tarde, la gran bailarina de los 30, Yol-Isma (cuyo nombre verdadero era Rebecca Viramontes) escribió un elogio al género:

\footnotetext{
${ }^{31}$ MATTHEWS, I. Mothering in war... Op. cit., pp.73-74.
}

32 QuIROz, M. T. Danza y poder. Op. cit.;p.117. 
Mary Louise Pratt

No hay en ningún pais espetaculo semejante, por la grandiosidad, por la riqueza de colorido y por lo bien actuado y bailado por los estudiantes y elementos que toman parte. ${ }^{33}$

Como la producción literaria femenina, la danza se perdió de vista en la historiografía de las artes pos-revolucionarias. La calidad efímera de la danza, sobre todo en la época pre-video, y la falta de otro tipo de documentación implica una distorsión permanente en nuestras reconstrucciones históricas, distorsión que además invisibiliza el único medio artístico donde predomina la creatividad de las mujeres.

\section{Contratexto, contradanza}

Se sugirió arriba que la danza improvisada e interrumpida de la madre en Las manos expresa el caos de la sociedad en estado de guerra, y presupone una norma, que sería la danza ritual o coreografiada, forma basada en la estabilidad y la paz. El ballet de masas parecería ejemplificar esa norma, celebrando la revolución no sólo como restauradora de orden, sino como inauguradora de un nuevo orden democrático. Según los historiadores de la danza, la carrera dancística de Campobello como coreógrafa y directora de la Escuela Nacional de Danza y fundadora del Ballet de la Ciudad de México fue dominada por una fuerte polémica entre un acercamiento desde el ballet clásico y la emergente "danza moderna" asociada con figuras como Martha Graham y, en México, Ana Sokolow y Waldeen. Fanática opositora de la danza moderna, Campobello y su talentosa hermana Gloria crearon una dancística original y única que fusionaba ballet clásico, baile indígena, temática nacionalista, y espectáculos de participación masiva. Su dogmatico rechazo de las corrientes "modernas" causó finalmente la marginación total de

33 MARTíneZ, César Delgado y JimÉnEZ, Julio C. Villalva. Yol-Izma: La danzarina de las leyendas. México, Escenología, 1997, p.112. 
Mi cigarro, mi Singer, y la revolución mexicana

Campobello del escenario dancístico mexicano. Muchos bailarines abandonaron su escuela por cause da la rigidez del programa y las exigencias excesivas. La creatividad improvisada e individual que se celebra en Las manos fue rechazada por Campobello en el escenario. Leer Las manos como contratexto y contradanza al ballet de masas es descubrir una voluntad personal y artística que se frustró en el escenario. La "batalla por la forma" notada en su texto literario fue también, parece, una batalla entre las enormes fuerzas creativas de Campobello misma.

\section{Post scriptum}

Después de la confirmación de la muerte de Campobello, su secuestrador Claudio Niño Cienfuentes Figueroa, quien seguía confirmando que hablaba regularmente con ella, fue encarcelado en el Reclusorio Oriente, desde donde transmitía un programa de radio semanal titulado "Crónicas desde la Cárcel". ${ }^{44}$ La periodista Raquel Peguero, cuyos reportajes mantuvieron el caso en la arena pública hasta su resolución, fue nominada por un prestigioso premio nacional de periodismo. No lo ganó: fue premiado un reportaje sobre el 40 aniversario de la muñeca Barbie.

En febrero de 2001 Cienfuentes Figueroa fue sentenciado a 27 años de prisión no sólo por el secuestro, sino por haber aprovechado de sus bienes, fingiendo que Campobello seguía en vida por 15 años después de su muerte. El veredicto, resultado de una investigación iniciada en 1998, fue declarado "Magnífico" por la procuradora de la Ciudad de México. Diez meses después, sin embargo, la sentencia fue revocada y Cienfuentes fue inmediatamente puesto en libertad. En setiembre de 2002 recibió una sentencia de absolución del crimen por parte del Tribunal Superior de Justicia de la ciudad de México, dos votos contra uno. El caso se considera cerrado.

${ }^{34}$ Ver artículos por PEGUERO, Raquel. La Jornada, 23 diciembre de 1999, p.49 y Manzanos, Rosario. Proceso, 14 marzo de 1999, p.50. Agradezco a Gabriela Cano por esta actualización. 